\title{
Author Correction: Conservation of copy number profiles during engraftment and passaging of patient-derived cancer xenografts
}

Xing Yi Woo (D), Jessica Giordano D, Anuj Srivastava, Zi-Ming Zhao, Michael W. Lloyd, Roebi de Bruijn, Yun-Suhk Suh, Rajesh Patidar, Li Chen, Sandra Scherer, Matthew H. Bailey, Chieh-Hsiang Yang, Emilio Cortes-Sanchez, Yuanxin Xi, Jing Wang (D), Jayamanna Wickramasinghe, Andrew V. Kossenkov, Vito W. Rebecca, Hua Sun, R. Jay Mashl, Sherri R. Davies (D), Ryan Jeon, Christian Frech, Jelena Randjelovic, Jacqueline Rosains, Francesco Galimi, Andrea Bertotti, Adam Lafferty, Alice C. O'Farrell (D), Elodie Modave, Diether Lambrechts (D), Petra ter Brugge, Violeta Serra (D), Elisabetta Marangoni (D), Rania El Botty, Hyunsoo Kim, Jong-II Kim D, Han-Kwang Yang, Charles Lee, Dennis A. Dean IIID, Brandi Davis-Dusenbery, Yvonne A. Evrard (D), James H. Doroshow, Alana L. Welm (D), Bryan E. Welm, Michael T. Lewis, Bingliang Fang, Jack A. Roth (D), Funda Meric-Bernstam, Meenhard Herlyn (D), Michael A. Davies (D), Li Ding, Shunqiang Li, Ramaswamy Govindan, Claudio Isella, Jeffrey A. Moscow (D), Livio Trusolino (iD, Annette T. Byrne, Jos Jonkers (D), Carol J. Bult, Enzo Medico (iD, Jeffrey H. Chuang (iD, PDXNET Consortium and EurOPDX Consortium*

Correction to: Nature Genetics https://doi.org/10.1038/s41588-020-00750-6, published online 7 January 2021.

This paper was originally published without open access. As of the date of this correction, the paper is available online as an open-access paper under a Creative Commons Attribution 4.0 International License.

${ }^{\star}$ Lists of authors and their affiliations appear online.

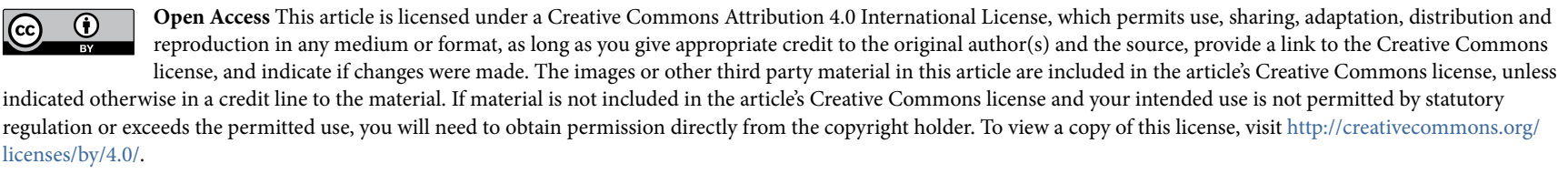

Published online: 19 February 2021

https://doi.org/10.1038/s41588-021-00811-4

() The Author(s) 2021

\section{Author Correction: Enhancer-promoter interactions and transcription}

Douglas R. Higgs (iD)

Correction to: Nature Genetics https://doi.org/10.1038/s41588-020-0620-7, published online 6 May 2020.

In the version of this article initially published, author Douglas R. Higgs was missing the affiliation National Institute of Health Research, Oxford Biomedical Research Centre, Oxford, UK. The error has been corrected in the HTML and PDF versions of the article.

Published online: 3 March 2021

https://doi.org/10.1038/s41588-021-00815-0

(c) Springer Nature America, Inc. 2021 